\title{
A POESIA EM SI MESMA: DESDOBRAMENTOS DE UM CONCEITO SEGUNDO SOPHIA DE MELLO BREYNER ANDRESEN
}

\author{
Bruno Anselmi Matangrano
}

RESUMO: Em busca de uma definição de poesia, o presente artigo procura analisar o texto "Poesia e Realidade" e os poemas "Liberdade" e "A Casa Térrea" da poetisa portuguesa Sophia de Mello Breyner Andresen, cotejando-os com a teórica do crítico francês Charles Dantzig, de modo a mostrar todas as nuances desse termo e seus múltiplos desdobramentos.

PALAVRAS-CHAVE: Teoria da Poesia; Poema; Sophia de Mello Breyner Andresen; Charles Dantzig;

RÉSUMÉ: À la recherche d'une définition de poésie, le présent article essaie d'analyser le texte «Poesia e Realidade» et les poèmes «Liberdade» et «A Casa Térrea » de la poétesse portugaise Sophie de Mello Breyner Andresen, en les comparant avec la théorie du critique français Charles Dantzig, de façon à montrer toutes les nuances de ce terme et leurs multiples dédoublements.

MOTS-CLÉS : Théorie de la Poésie ; Poème; Sophia de Mello Breyner Andresen; Charles Dantzig;

\section{Introdução: Em busca de uma definição de poesia}

Não foi a postura permanentemente ereta que separou o homem do macaco: foi a poesia. ${ }^{2}$

(Charles Dantzig)

Todo mundo tem uma vaga ideia do que é "poesia"; poucos - à exceção dos especialistas - hesitariam em chamar de poesia todo e qualquer poema, e alguns outros, na tentativa de explicitar o quanto se impressionaram pela beleza de algum objeto, obra de arte, ato ou emoção, empregariam a palavra "poético", na esperança de com ela dar conta de toda uma infinidade de sensações e sentimentos suscitados. Não obstante, designar o que é a "poesia" não é algo tão simples, ainda que o termo tenha sido vulgarizado, pois, como explica o crítico e escritor francês Charles Dantzig, no mesmo texto do qual se extraiu a epígrafe acima: "Os homens vivem de poesia, mas não sabem disso." ${ }^{3}$ (DANTIZ, 2008, p. 793). O crítico francês justifica essa sua afirmação pelo

\footnotetext{
${ }^{1}$ Bacharel em Letras pela Faculdade de Letras, Filosofia e Ciências Humanas da Universidade de São Paulo (USP), com habilitação em português e em francês. Atualmente, é aluno do curso de Mestrado do programa de pós-graduação em Literatura Portuguesa da mesma instituição. É bolsista da Fundação de Amparo à Pesquisa do Estado de São Paulo (FAPESP). Contato: bamatangrano@ yahoo.com.br

${ }_{2}$ «Ce n'est pas la station debout permanente qui a séparé l'homme du singe : c'est la poésie. ». (Todos os trechos citados em francês foram traduzidos por mim).

3 «Les hommes vivent de poésie, mas ils ne le savent pas. »
} 
fato de o homem estar inserido em um mundo, segundo ele, poético, em maior ou menor grau; considera possível encontrar a poesia em qualquer lugar mesmo que deturpada, e cita como exemplo desde livros e filmes até anúncios publicitários nos quais vislumbra um resquício do fazer poético através da constante intertextualidade, de rimas, de fórmulas.

Contudo, saber que a poesia se encontra em toda parte não dá conta de explicar o que esse termo significa e, muito menos, o que esse termo significa, particularmente, para a poetisa portuguesa Sophia de Mello Breyner Andresen, a qual o teorizou no texto “Poesia e Realidade", publicado em 1960 na revista Colóquio. Revista de Artes e Letras. Antes de tudo, importa lembrar que Sophia considera que qualquer tentativa de definição da palavra "poesia" será insuficiente dada a quantidade de coisas e significações que a ela são atribuídas; ainda assim, ela fornece interessante definição e começa, justamente, precisando que para o termo poesia há, ao menos, três acepções evidentes: "Para tornar claro o que vou dizer, chamarei Poesia à poesia em si, poesia à relação do homem com a Poesia e poema à linguagem da poesia." (ANDRESEN, 1960, p. 53).

Para ela a Poesia, com "P" maiúsculo, é algo que independe do homem e está em toda parte, aproximando-se, pois, daquilo que Dantzig vê como poesia e na qual, justamente por estar em toda parte, o homem está embebido, uma vez que a "Poesia é a própria existência das coisas em si, como realidade inteira, independente daquele que a conhece.” (ANDRESEN, 1960, p. 53) Nesse mesmo caminho, Dantzig dirá: “A poesia não descreve o sentimento ou a coisa, ela o é." (DANTZIG, 2008, p. 792). ${ }^{4}$

Já a poesia com "P" minúsculo é a "relação do homem com a realidade, tomando-a na sua pura existência." (ANDRESEN, 1960, p. 53). Em um sentido mais estrito, poder-se-ia dizer, a poesia é o próprio exercício do fazer poético. É a produção de uma obra artística que traduza as sensações e sentimentos suscitados pelo contato do poeta/artista com a realidade.

Por fim, o poema é o fruto do fazer poético: "O poeta vê a Poesia, vive a poesia e faz o poema." (ANDRESEN, 1960, p. 54). Para Sophia, as duas primeiras independem do homem, "não são criação. São realidade e vivência.", enquanto o poema é criação. Nesse sentido, Dantzig afirma: “A poesia é a forma superior da imaginação. É por isso

\footnotetext{
${ }^{4}$ « La poésie ne décrit pas le sentiment ou la chose, elle l'est. »
} 
que se crê ser ela aparentada ao divino [...]. Poesia é trabalho. Dela resulta um canto que faz com que se acredite que ela se passe no céu." (DANTZIG, 2008, p. 791). ${ }^{5}$ Nesse caso, entende-se "poesia" como "poema", como bem destacou Sophia. Ou seja, o poema é o trabalho do poeta em expressar sua relação com uma realidade.

Uma vez, portanto, entendido como Sophia define a ideia de poesia e de suas nuances (Poesia, poesia e poema) - definição esta corroborada pela definição de Dantzig -, parte-se, enfim, para a leitura de dois poemas metalinguísticos que se debruçam, a um só tempo, sobre a questão do poema e a do fazer poético. São eles: "Liberdade" e "A Casa Térrea".

\section{Dois poemas sobre poesia}

Em seu texto "Sophia: A Lírica e a Lógica", Eduardo Prado Coelho aponta o quanto é difícil para a crítica se voltar para textos de bons escritores contemporâneos, uma vez que poetas como Sophia apresentam uma tal "limpidez de linguagem" que dificilmente se autorizaria "a sua duplicação sob a forma de comentário". (COELHO, 1984, p. 109). Isso significa que esses textos são bastante claros, o que não quer dizer, evidentemente, que sejam superficiais; ao contrário, significa que o autor tem a capacidade de dizer o que quer de forma clara e em dada medida simples, no melhor sentido da palavra. Assim o são os poemas de Sophia, que embora não apresentem dificuldade de leitura, proporcionam desafios à interpretação. Dito isso, passa-se aos poemas, a começar por "Liberdade":

\section{LIBERDADE}

O poema é

A liberdade

Um poema não se programa

Porém a disciplina

- Sílaba por sílaba -

O acompanha

Sílaba por sílaba

O poema emerge

- Como se os deuses o dessem

O fazemos

\footnotetext{
${ }^{5}$ «La poésie est la forme supérieure de l'imagination. C'est pour cela qu'on la croit apparentée à la divination [...]. La poésie, c'est du travail. Il en résulte un chant faisant croire qu'elle se passe dans le ciel. »
} 
Pode-se dizer já numa primeira leitura que esse poema é, em si, uma representação dessa liberdade já evocada pelo título. Poema breve, sem forma precisa, sem rimas, sem pontuação, é um exemplo da liberdade formal que a poesia lírica (poesia aqui como gênero literário) adquiriu ao longo dos séculos XIX e XX. Os dois primeiros versos só vêm a confirmar essa leitura: "O poema é/ A liberdade"; contudo, ao dizer isso o texto adquire um papel ainda maior, pois não quer dizer que há liberdade no fazer poético, e sim que o poema é a própria representação da liberdade. Em última instância, poder-seia questionar a possibilidade de liberdade para além do poema. $\mathrm{O}$ ato de escrever seria uma espécie de liberdade absoluta, e essa leitura se confirma ao se cotejar esse poema com o texto "Poesia e Realidade" comentado no início, no qual Sophia diz a propósito da poesia (com "P” minúsculo): “O poema vem como um intermediário, é ele que torna possível que a poesia não se quebre contra os seus próprios limites. Podemos dizer por isso que o poema é liberdade." (ANDRESEN, 1960, p. 54). Ao dizer isso, Sophia explica que tudo é matéria para um poema, posto que este seja a representação física da relação do poeta com a realidade.

Na segunda estrofe, Sophia vai mostrando como o exercício poético se efetua: não é algo que possa ser programado, embora exija disciplina (interessa lembrar que Dantzig diz: "Poesia é trabalho"). Essa disciplina é afinal o ofício do poema que se dedica a traduzir a Poesia (com "P" maiúsculo) em poema, e esse ato seria "uma forma de transformar em coisas nosso amor pelas coisas". (ANDRESEN, 1960, p. 54)

Na terceira e última estrofe, fica ainda mais evidente o trabalho do poeta, a partir do qual o "poema emerge", pouco a pouco, "sílaba por sílaba". O terceiro verso dessa estrofe, porém, parece sugerir que o fazer poético também depende de "inspiração", quase como um dom divino, como se a um só tempo houvesse a inspiração e o trabalho do poema, como acreditavam os gregos (tão admirados por Sophia) e os românticos oitocentistas. Não obstante, o uso do vocábulo comparativo "como" parece enfraquecer essa hipótese, a qual se atenua ainda mais pelo verso final: "O fazemos". É somente nesse verso que um "eu" se coloca, tornando um pouco mais pessoal, o que até então era estritamente impessoal. A escolha do verbo "fazer" também é significativa, pois mostra o papel ativo do poeta que afinal é dotado de "disciplina" e "acompanha" atentamente "sílaba por sílaba". "Fazer" e "acompanhar" se confrontam, assim como as noções de 
trabalho e inspiração. É na tensão que se faz o poema e é da tensão que nasce a sua liberdade.

Bastante diferente de "Liberdade", mas ainda assim metapoético, "A Casa Térrea" parece ser um pouco mais complexo, não quanto à sua forma - também bastante livre -, mas no que concerne ao seu conteúdo.

\section{A CASA TÉRREA}

Que a arte não se torne para ti a compensação daquilo que não soubeste ser

Que não seja transferência nem refúgio

Nem deixes que o poema te adie ou divida: mas que seja

A verdade do teu inteiro estar terrestre

Então construirás a tua casa na planície costeira

A meia distância entre montanha e mar

Construirás - como se diz - a casa térrea -

Construirás a partir do fundamento

Três verbos da primeira estrofe estão no imperativo - "não se torne", "não seja", "nem deixes" -, o que sugere já de início um "tu” que recebe conselhos do eu-lírico. Esses conselhos giram em torno da questão do fazer poético já tratado no poema "Liberdade", todavia questões um pouco mais complexas são introduzidas em "A Casa Térrea". A "arte", em sentido geral, e a "poesia", em sentido mais estrito, não deve ser, segundo o poema, uma compensação para as frustrações da vida, tampouco lugar de refúgio. A arte/poema deve ser a "verdade", o que corrobora a ideia de Sophia de que a poesia é o meio pelo qual o homem se relaciona com a realidade.

Dizer que na poesia não se deve buscar refúgio nem compensar as frustrações exemplifica uma atitude constante da poesia de Sophia: ver o fazer poético com bons olhos. A esse respeito comenta Eduardo Lourenço, comparando-a com Pessoa, que via a lucidez do poeta como uma espécie de tormento, uma vez que o conhecimento traria, para ele, sofrimento enquanto a ignorância seria uma espécie de acalento:

$\mathrm{Na}$ topologia de nossa aventura poética, Sophia e Pessoa ocupam os polos opostos e nesse sentido a poesia de Sophia, de uma maneira bem diversa e muito mais radical que a de poetas que conscientemente se quiseram outros que Pessoa, inaugura ou põe termo à longa travessia da consciência poética como consciência infeliz que começa em Antero e tem em Álvaro de Campos a sua expressão "épica". (LOURENÇO, 1978, p. V) 
O sujeito poético de "A Casa Térrea" é, pois, otimista em relação ao ofício do poeta, desde que o objetivo do fazer poético seja a busca de uma verdade ou da representação da relação do homem com uma realidade. Uma vez transformada em refúgio ou consolo, a poesia parece já não lhe ter o mesmo poder.

A segunda estrofe, por outro lado, não apresenta o mesmo tom incisivo dos conselhos da primeira; com verbos no futuro, tenta mostrar como será tudo se o "tu" seguir os conselhos oferecidos. Nessa passagem Sophia introduz três temas importantes dos quais dois lhe são bastante caros: a casa, o mar e a montanha.

Segundo Coelho, o "mar", assim como a "luz", é, na obra de Sophia, símbolo da perfeição (COELHO, 1984, p. 123), mas é também o "mar" uma referencia à infinitude, posto que se abre e se estende além do que a visão humana pode enxergar, sugerindo uma vastidão e uma liberdade. A casa do "tu" que virá a ser poeta deve se localizar entre o mar e a montanha, numa planície. A “montanha” é símbolo do que é elevado, aponta para o céu, evoca sutilmente o divino. Essa casa se situaria, pois, entre a liberdade e o divino, o que remeteria novamente ao poema "Liberdade", comentado anteriormente. Uma vez feita essa relação, a "casa" pode ser lida como o próprio "poema" que será "construído" pelo poeta, entre a "liberdade" proporcionada pelo "mar" e a inspiração divina. Os conselhos da primeira estrofe parecem, por conseguinte, ser a "fórmula" pra a construção de um poema como o descrito em "Liberdade", e, para tanto, é necessário disciplina.

Para Sophia a "cidade" é sempre algo desvalorizado, em oposição à Natureza, aqui representada na "montanha" e no "mar". Coelho atenta, porém que: "A desvaloração da cidade opõe-se, contudo, o valor da casa.” (COELHO, 1984, p. 119) Já que a casa é o lugar seguro, maternal, de aconchego, em oposição ao caos da cidade. “Observa-se [...] o valor da casa como lugar eufórico: tal como o tempo dividido separa do chão e da parede da casa primitiva, a morte é definida como um abandonar a casa e um descer à cidade." (COELHO, 1984, p. 122) A casa é o lugar de inspiração e de trabalho, é ao mesmo tempo o poema e o seu lugar de origem.

Os dois últimos versos trazem ainda novas imagens. A casa é especificada, é uma casa térrea, ou seja, a casa-poema não deve apontar rumo ao céu como a montanha, ao contrário, deve estar rente ao chão, numa planície, junto ao mar. Afinal, o poema é realidade e trabalho do homem, construído pelo poeta disciplinado que seguiu os 
conselhos e buscou a verdade do inteiro estar terrestre. A poesia não transcende, não busca o divino, e sim traduz a realidade, ou, melhor dizendo, traduz a relação do homem com a realidade. Esse parece ser o "fundamento".

Parece necessário, contudo, duas palavras acerca do vocábulo "fundamento". De acordo com o Dicionário Barsa da Língua Portuguesa (1982, p. 504): Fundamento, s.m. pode significar tanto: “1. Base, alicerce.” quanto: “2. Motivo, razão.” E ambos os sentidos parecem se enquadrar na leitura que está sendo proposta ao poema. O "fundamento" é a base e o alicerce da "casa térrea", é sobre ele que ela se estrutura e se constrói. Assim também o é o poema que sobre um motivo ou uma razão é feito, e, para Sophia, a razão de existir do poema é a necessidade do homem - ou de alguns homens de encontrar a essência das coisas através de sua relação com elas: "O poeta não tem curiosidade do Real, mas sim necessidade do Real. A verdadeira ânsia dos poetas é uma ânsia de fusão e de unificação com as coisas.” (ANDRESEN, 1960, p. 53) É essa ânsia que deve ser o fundamento da poesia, essa fusão das coisas, é disso que se faz o poema e a poesia e é disso que sobressai "A verdade do teu inteiro estar terrestre". A poesia não se faz, pois, de medos e frustrações, tampouco se faz naquilo que é divino, sua matéria é a vivência do poeta, o terrestre, sua simplicidade de casa térrea, esse, parece, é o seu fundamento. Em outras palavras, o "fundamento" do poema nada mais é do que “poesia”, com "P” minúsculo, e a verdadeira "poesia”, só nasce da liberdade.

\section{Conclusão:}

Sophia busca, pois, entrar em contato com a Poesia para produzir seus poemas. Seu fazer poético é livre, assim como também o é a forma que ela emprega em suas poesias, e essa liberdade na busca pelo Real, é o seu fundamento. Dizer, porém, que sua forma é "livre" não significa dizer que ela não faça uso de formas fixas, mas, sim, que possui a liberdade de escolher entre uma possibilidade poética e outra; a esse respeito dirá Dantzig: “A poesia é a combinação de uma forma estudada e de uma emoção comunicada. Não há oposição entre forma e emoção: uma bela forma pode procurar uma emoção; uma forte emoção pode ser traduzida em uma forma perfeita." (DANTZIG, 2008, p. 792) ${ }^{6}$

\footnotetext{
${ }^{6}$ «La poésie est la combinaison d'une forme étudiée et d'une émotion communiquée. Il n’y a pas d'opposition entre forme et émotion : une belle forme peut procurer une émotion, une forte émotion peut être traduite dans une forme parfait. »
} 
A forma perfeita para Sophia é aquela que traduz sua emoção, e sua emoção se traduz pela liberdade, esse parece, pois, ser, ao menos nos dois poemas lidos e no texto comentado, seu fundamento - o resto é talvez um pouco de inspiração, mas certamente muito trabalho e disciplina.

\section{Bibliografia:}

ANDRESEN, Sophia de Mello Breyner. "Poesia e Realidade", in Colóquio. Revista de Artes e Letras, $\mathrm{n}^{\circ}$ 8, abril de 1960.

COELHO, Eduardo Prado. A Mecânica dos fluidos - literatura, cinema, teoria. Lisboa: Imprensa Nacional - Casa da Moeda, 1984.

DANTZIG, Charles. Dictionnaire égoïste de la littérature française. Paris : Librairie Générale Française, 2008.

Dicionário Barsa da língua Portuguesa Ilustrado. 2. Vol. Rio de Janeiro; São Paulo: Encyclopaedia Britannica do Brasil Publicações LTDA., 1982.

LOURENÇO, Eduardo. "Para um retrato de Sophia", in ANDRESEN, Sophia de Mello Breyner. Antologia. Lisboa: Moraes Editores, 1978. (Col. Círculo de Poesia). 